\title{
A problemática na definição da jurisdição penal para os crimes cometidos a bordo de embarcação mercante em passagem inocente $^{*}$
}

\section{The problem in the definition of criminal jurisdiction for crimes committed the vessel on board merchant in innocent passage}

Ingrid Zanella Andrade Campos ${ }^{1}$ Leonardo Henrique Siqueira ${ }^{2}$
Recebido em: 02/02/2016.

Aprovado em: 08/08/2016.

Professora do Programa de Pós-Graduação em Direito da Faculdade Damas da Instrução Cristã. Doutora e Mestre pela Direito na Universidade Federal de Pernambuco (UFPE). Professora Adjunta da Universidade Federal de Pernambuco (UFPE). Auditora Ambiental Líder. Perita Ambiental Judicial. Coordenadora e Professora da Pós-Graduação em Direito Marítimo, Portuário e do Petróleo da UNINASSAU/PE. Professora das especializações em Direito Marítimo, Portuário e Ambiental da UNISANTOS/SP, Faculdade de Direito de Vitória/ES, UNIVALI/SC e UFRN. Presidente da Comissão de Direito Marítimo, Portuário e do Petróleo da OAB/PE. Membro da Comissão de Meio Ambiente da OAB/ PE. Oficial do Conselho da Ordem do Mérito Naval/Marinha do Brasil. Advogada no escritório Zanella Advogados \& Consultores (<www. zanellaconsultoria.adv.br $>$ ). E-mail: ingrid@zanellaconsultoria.adv.br. Professor do Programa de Pós-Graduação em Direito da Faculdade Damas da Instrução Cristã. Doutor e Mestre em Direito pela Universidade Federal de Pernambuco (UFPE).

\begin{abstract}
Resumo
A problemática da definição da jurisdição penal, para crimes cometidos a bordo de embarcações, representa um dos grandes temas atuais das relações jurídicas internacionais que se inscrevem dentro do núcleo das novas perspectivas do Direito Internacional do Mar. No presente artigo, analisar-se-á o Direito Internacional Penal, com destaque ao aspecto marítimo, por meio de uma apreciação dos tratados e convenções bilaterais que tentaram definir a referida jurisdição, desde uma perspectiva histórica até uma abordagem internacionalista. Da mesma forma, apresentar-se-á a atual interpretação jurisdicional das cortes brasileiras e uma revisão bibliográfica a respeito da matéria. A pesquisa tem caráter histórico e documental e os resultados preliminares apontam para a existência da predominância da jurisdição penal do Estado de Bandeira em crimes cometidos a bordo de embarcações em passagem inocente no Mar Territorial brasileiro.
\end{abstract}

Palavras-chave: Jurisdição penal. Embarcações mercantes. Direito Penal Internacional. Direito Marítimo.

\begin{abstract}
The issue of criminal jurisdiction for crimes committed on board of merchant vessels is one of the major current issues of international legal relations that fall within the core of the new perspectives of the Sea International Law. In this article we analyze shall be the International Criminal Law, especially the maritime aspect, through an appreciation of the treaties and bilateral agreements that attempted to define that court from a historical perspective to an internationalist approach. Similarly, it will present the current judicial interpretation of Brazilian courts and a literature review on the matter. Research has historical and documentary character and preliminary results point to the existence of the predominance of criminal jurisdiction Flag State for crimes committed on board vessels on innocent passage in the Brazilian Territorial Sea.
\end{abstract}

Keywords: Criminal jurisdiction. Merchant vessels. International Criminal Law. Maritime law. 


\section{Introdução}

O artigo tem como escopo a problemática subjacente à definição da jurisdição penal em crimes ocorridos a bordo de embarcação estrangeira realizando o direito de passagem inocente no Mar Territorial brasileiro, trazendo uma visão contemporânea por meio do entendimento jurisprudencial das Cortes brasileiras e doutrinário dos Tratados Internacionais. A doutrina pátria se mostra alienada em relação ao tema e, às cegas, conduz no mínimo a uma interpretação paradoxal e descontínua se pensarmos na solução normativa dada pelos Tratados Internacionais.

Deparar-se-á com a hipótese de que mesmo o Mar Territorial sendo espaço marítimo brasileiro e a regra geral é a territorialidade, caso ocorra um crime a bordo de embarcação estrangeira realizando o direito de passagem inocente no referido espaço marítimo, dever-se-ia aplicar a lei penal do Estado da Bandeira, com exceções especificamente estabelecidas, pois o Brasil é signatário de tratados internacionais que tratam a matéria e estabelecem uma jurisdição excepcional para o caso citado.

Pretende-se, inicialmente e como objetivo específico, traçar uma diferença básica, contudo essencial, entre Direito Penal Internacional e Direito Internacional Penal, para demonstrarmos que o nosso objeto de pesquisa se relaciona com o estudo da Lei Penal no Espaço. Tal abordagem descreverá o princípio da territorialidade, regra geral e normatizada no nosso Código Penal, e os princípios que constituem verdadeiras exceções e permitem à lei penal extrapolar os limites territoriais do Estado.

Em seguida, a fim de compreender a referida problemática sob um viés histórico-normativo, desenvolve-se o conceito de território e exposição dos tratados internacionais que trataram do tema, de modo a evidenciar a construção do panorama dogmático acerca da delimitação da jurisdição penal em Mar Territorial.

Desenvolver-se-á o conceito da passagem inocente, que deve ser entendida como possibilidade de navegação pelo mar territorial de outros Estados soberanos, desde que tenha ou a finalidade de atravessar esse mar sem penetrar nas águas interiores e nem fazer escala num ancoradouro ou instalação portuária situada fora das águas interiores ou tenha a finalidade de se dirigir para as águas interiores ou delas sair ou fazer escala num desses ancoradouros ou instalações portuárias. -se-á uma análise da Convenção das Nações Unidas sobre o Direito do Mar, em especial como a referida convenção trata da questão pertinente a jurisdição penal para os delitos cometidos na embarcação estrangeira em passagem inocente dentro do mar territorial do Estado Costeiro. Examinaremos da mesma forma o Código Bustamante e as suas disposições normativas sobre a competência dos Estados signatários para processar e julgar os crimes cometidos a bordo de navio estrangeiro.

Percorrido todo o caminho estabelecido pelos objetivos especiais, pretende-se demonstrar, como objetivo geral, que, caso ocorra um crime a bordo de embarcação estrangeira realizando o direito de passagem inocente no Mar Territorial, dever-se-ia aplicar, em regra, a jurisdição do Estado de Bandeira.

$\mathrm{O}$ artigo foi elaborado seguindo o método dedutivo, partindo-se das premissas até a conclusão. A constatação da veracidade das premissas permite atestar, pelos encadeamentos lógicos realizados com argumentos condicionais, a verdade da conclusão.

\section{Direito penal internacional e espaços maríti- mos}

\subsection{Delimitando o objeto de investigação: a distin- ção entre o Direito Penal Internacional e o Di- reito Internacional Penal}

O Direito Internacional Penal, cuja expressão International Criminal Law - fora cunhada no início do século XIX ${ }^{3}$, padeceu de vários questionamentos doutrinários, tanto por penalistas como por internacionalistas. No seio de tais discussões, restou claro que era necessário distinguir os diferentes objetos de estudo, uma vez que, até então, permaneciam indistintos.

Surge, dessa forma, a distinção entre o Direito Penal Internacional e o Direito Internacional Penal. Sob a alcunha do Direito Penal Internacional compreendemos todas as disposições sobre o alcance, aplicação e a validade espacial das normas internas de um Estado soberano ${ }^{4}$.

Delimita-se, também, o que estaria compreendido na esfera do Direito Internacional Penal, ou seja, um ramo do direito internacional público que trata da maté-

RIPOLLÉS, Antonio Quintano. Tratado de derecho penal internacional e internacional penal. Madrid: Instituto Francisco de Vitória,1955. v. 1.p. 11.

4 DIAS, Jorge de Figueiredo. Direito penal: parte geral. Coimbra: Coimbra Editora, 2007. t. 1. p. 207. 
ria penal a partir da criação de crimes e internacionais ${ }^{5}$. Discorrendo sobre o tema, Ferri ${ }^{6}$ demonstra uma preocupação "mundial" por uma justiça penal internacional já no fim do século XIX e início do século XX, ao falar das convenções de Haia de 1899 e de 1907, bem como no Pacto da Sociedade das Nações - inserido no Tratado de Versalhes de 1919 -, discutindo-se as exigências práticas de defesa comum contra os delinquentes cosmopolitas.

Explica Valério Mazzuoli que o direito penal internacional é o ramo do direito interno relativo às relações com os ordenamentos jurídicos estrangeiros e com a jurisdição estrangeira, competente para determinar a competência dos órgãos internos para a repressão de delitos na órbita internacional, em oposição ao chamado direito internacional penal, no qual a precedência do adjetivo 'internacional' induz tratar-se de um ramo do direito internacional concernente à tipificação internacional de delitos por meios de tratados, ao estabelecimento de cortes penais internacionais e à consequente responsabilidade penal dos indivíduos frente ao Direito Internacional Público ${ }^{7}$.

A discussão sobre a aplicação ou não da lei penal brasileira a bordo de embarcação mercante, em todos os seus aspectos, é objeto do direito penal internacional, tornando imprescindível delinear os principais aspectos para o exercício do poder punitivo pelo Estado nos casos onde existe uma relação internacional envolvida.

Desenvolve-se, então, os princípios do Direito Penal Internacional, em que a territorialidade é vista como o princípio de maior hierarquia, importância e destaque. Isto porque o princípio leva em consideração que, em relação aos limites territoriais de um Estado, a sua soberania lhe garante o poder exclusivo e autônomo para investigar e punir os delitos ocorridos dentro do seu território, excluindo-se qualquer outro ordenamento jurídico estrangeiro ${ }^{8}$.

O sistema jurídico-penal brasileiro admite como regra geral a territorialidade, conforme se depreende do disposto no artigo $5^{\circ}$ do nosso Código Penal. Todavia,

ASÚA, Luis Jiménez. Tratado de derecho penal. Buenos Aires: Losada, 1950. t. 2. p. 757.

6 FERRI, Enrico. Princípios de direito criminal: o criminoso e o crime. Campinas: Bookseller, 2003. p. 162-164. MAZZUOLI, Valério de Oliveira. Tribunal penal internacional e o direito brasileiro. São Paulo: Premier Máxima, 2005. p. 19

8 GRISPIGNI, Filippo. Derecho penal italiano: las normas penales sintéticamente consideradas. Buenos Aires: Depalma, 1949. v. 1. p. 417. não podemos entender a territorialidade como um princípio absoluto, até mesmo porque o artigo $7^{\circ}$ do mesmo diploma legal estabelece casos de extraterritorialidade da lei penal brasileira, fundamentados nos princípios da defesa, nacionalidade, justiça universal e da bandeira.

Além dos princípios complementares a territorialidade, é importante salientar que a decisão jurídica acerca dos limites do poder punitivo interno deve levar em consideração as convenções, tratados e regras de Direito Internacional, pois, como afirma Jescheck ${ }^{9}$, nenhum Estado deveria atribuir a si mesmo o poder punitivo para fatos que não evidenciam qualquer relação com os seus interesses legítimos na administração da justiça. Caso ocorra tal atribuição do poder punitivo, podemos contrapô-lo ao princípio da proibição de abuso de direito que foi consagrado e incorporado ao Direito Internacional.

\subsection{Princípio da Territorialidade e delimitação dos Espaços Marítimos}

Apesar dos Princípios da extraterritorialidade e das regras de Direito Internacional terem importância no estudo do Direito Penal Internacional, conforme vimos acima, é necessário, em um primeiro momento, focar os esforços doutrinários no exame do Princípio da Territorialidade e, consequentemente, no conceito de território marítimo ${ }^{10}$.

Segundo Asúa ${ }^{11}$, o Princípio da Territorialidade deixa claro que a lei penal de um Estado, em virtude da sua soberania, deve ser aplicada aos crimes perpetrados no seu território, sem levar em consideração a nacionalidade do autor ou do titular do bem jurídico lesionado.

Não sem razão, em face da adoção do referido princípio como regra geral no tocante à lei penal no espaço, definir o conceito de território e desenvolver teorias sobre o lugar do delito, demonstrou-se imprescindível.

No exame do conceito de território, dar-se-á ênfase a definição de território marítimo. Porém, antes de se adentrar na discussão sobre os espaços marítimos, ressalte-se que a demarcação do território de um Estado não se submete a delimitações puramente geográficas, apesar de partir do âmbito abarcado pelo território no sentido geográfico. Sendo assim, a definição de território é, no

9 JESCHECK, Hans-Heinrich. Tratado de derecho penal: parte general. Granada: Comares, 2002. p. 176.

10 BRANDÃO, Cláudio. Curso de direito penal: parte geral. Rio de Janeiro: Forense, 2010. p. 90

11 ASÚA, Luis Jiménez. La ley y el delito: princípios de derecho penal. Buenos Aires: Sudamericana, 1958. p. 161. 
fundo, o conceito jurídico de território, sendo equivalente ao espaço onde o Estado exerce a sua soberania ${ }^{12}$.

Registre-se que apenas na III Conferência das Nações Unidas sobre o Direito do Mar, que ocorreu em 1973, em Montego Bay (Jamaica), foi possível definir os espaços marítimos com as respectivas jurisdições dos Estados soberanos. A mencionada conferência perdurou até 1982 com a firmação da Convenção das Nações Unidas sobre o Direito do Mar (CNUDM). A CNUDM entrou em vigor internacionalmente em 1994, onde o Brasil assinou em 1982, ratificou em 1988 e promulgou pelo Decreto-Lei no 1530/1995.

A CNUDM consagrou os conceitos do território marítimo, definiu o mar territorial a zona econômica exclusiva e a plataforma continental, bem como tratou da poluição marinha, buscando a preservação do meio ambiente. A Convenção criou três órgãos: Comissão de Limites da Plataforma Continental para além das $200 \mathrm{mi}$ lhas; Autoridade Internacional dos Fundos Marinhos; e Tribunal Marítimo Internacional.

No Brasil, a Lei no 8.617, de 04 de janeiro de 1993 dispõe sobre o mar territorial, a zona contígua, a zona econômica exclusiva e a plataforma continental brasileiros, e dá outras providências.

O Mar Territorial (MT) é a faixa de mar adjacente ao território, além das águas interiores. Este se estende desde a linha de base (linha de baixa-mar ao longo da costa) até o limite até 12 (doze) milhas (máximo).

Esclarece-se, desde já, que a milha náutica é o comprimento do arco de 01 (um) minuto do perímetro médio do globo terrestre. Como a terra não é rigorosamente esférica, seu valor varia se a medida for adotada num meridiano ou no equador. A milha náutica é igual a 1.853,55 metros, que é a média da medida de um minuto no meridiano e um minuto no equador.

De acordo com a CNUDM, todo Estado tem o direito de fixar a largura do seu mar territorial até um limite que não ultrapasse 12 (doze) milhas marítimas, medidas a partir de linhas de base determinadas de conformidade com a Convenção em glosa.

Já a Lei $n^{\circ} 8.617 / 93$, art. $1^{\circ}$, fixou o mar territorial em 12 milhas, afirmando que o mar territorial brasileiro compreende uma faixa de doze milhas marítima de largura, medidas com base na linha de baixa-mar do litoral continental e insular.
12 CONDE, Francisco Muñoz; ARÁN, Mercedes García. Derecho penal: parte general. Valência: Tirant Lo Blanch, 2004. p. 154.
Segundo Bonavides, o Mar Territorial é aquela faixa variável de águas que banham as costas de um Estado e sobre as quais exerce ele direitos de soberania ${ }^{13}$.

A soberania do Estado costeiro estende-se além do seu território e das suas águas interiores e, no caso de Estado arquipélago, das suas águas arquipelágicas, a uma zona de mar adjacente designada pelo nome de mar territorial. Esta soberania estende-se ao espaço aéreo sobrejacente ao mar territorial, bem como ao leito e ao subsolo deste mar.

O mar territorial inclui o espaço aéreo, o leito e o subsolo do mar, sendo, ainda, considerado bem da União, de acordo com o art. 20, VI, da Constituição da República Federativa do Brasil de 1988. Destaca-se, que, para Rezek, "O Estado exerce soberania plena sobre os ares situados acima de seu território e de seu mar territorial"14.

A Zona Contigua (ZC) é a faixa de mar adjacente ao mar territorial, que não pode se estender por mais de 12 (doze) milhas desse espaço marítimo, ou 24 (vinte e quatro) milhas a partir da linha de base que serve para medir a largura do mar territorial. É o espaço marítimo destinado à segurança do o Estado costeiro no que tange a faculdades de fiscalização e repressão de atos que violem alguns de seus direitos internos.

Nesse espaço marítimo, o Estado costeiro possui, de acordo com o artigo 33, da CNUDM, e $4^{\circ}$, da Lei ${ }^{\circ}$ 8617/1993, jurisdição legal e específica para fins de fiscalização no que tange à: alfândega, saúde, imigração nos portos, em matéria fiscal e para evitar infrações legais.

$\mathrm{Na}$ zona contígua, o Brasil poderá tomar as medidas de fiscalização necessárias para evitar as infrações às leis e aos regulamentos aduaneiros, fiscais, de imigração ou sanitários, no seu território ou no seu mar territorial; e, reprimir as infrações às leis e aos regulamentos, no seu território ou no seu mar territorial (art. $5^{\circ}$, Lei n ${ }^{\circ}$ 8.617/1993)

O Estado costeiro na zona contígua possui jurisdição legal e específica para fins de fiscalização no que tange à alfândega, saúde, imigração nos portos, matéria fiscal. Podendo, tomar medidas necessárias para evitar e reprimir infrações.

A Zona Econômica Exclusiva (ZEE) compreende uma faixa que se estende das doze às duzentas milhas ma-

13 BONAVIDES, Paulo. Ciência política. 10. ed. São Paulo: Malheiros, 2000. p. 109.

14 REZEK, Francisco. Direito internacional público. 10. ed. São Paulo: Saraiva, 2005. p. 326. 
rítimas, contadas a partir das linhas de base que servem para medir a largura do mar territorial. É a Faixa de mar adjacente ao mar territorial, que não integra o território do Estado nem o Alto-Mar.

A largura da ZEE é de 200 (duzentas) milhas a contar da linha de base do mar territorial ou 188 (cento e oitenta e oito) milhas a contar do limite exterior do mar territorial.

O objetivo da fixação da ZEE é para proteger direitos dos Estados costeiros relativamente à pesca e extração de recursos vivos, proteção do desenvolvimento dos países em desenvolvimento.

$\mathrm{Na} Z \mathrm{ZEE}$, o Estado costeiro possui direitos de soberania para fins de exploração e aproveitamento, conservação e gestão dos recursos naturais, vivos ou não vivos, das águas sobrejacentes ao leito do mar, do leito do mar e seu subsolo e no que se refere a outras atividades com vista à exploração e aproveitamento da zona para fins econômicos, como a produção de energia a partir da água, das correntes e dos ventos.

Ainda há jurisdição, de conformidade com as disposições pertinentes da presente Convenção, no que se refere à colocação e utilização de ilhas artificiais, instalações e estruturas; investigação científica marinha; proteção e preservação do meio marinho.

Percebe-se que o Estado costeiro tem uso exclusivo para aproveitamento e conservação dos recursos naturais, investigação científica e preservação do meio ambiente. Logo, há uma jurisdição preservacionista e investigatória, ligada à exploração econômica.

$\mathrm{Na} Z \mathrm{ZEE}$, todos os Estados, quer costeiros quer sem litoral, gozam das liberdades de navegação e sobrevoo e de colocação de cabos e dutos submarinos, bem como de outros usos do mar internacionalmente lícitos, relacionados com as referidas liberdades, tais como os ligados à operação de navios, aeronaves, cabos e dutos submarinos.

No que tange às manobras militares, o artigo $9^{\circ} \mathrm{da}$ Lei no 8.617/93 defende que essas manobras precisam de consentimento, entretanto a CNUDM nada afirma sobre esse ponto.

Conforme a CNUDM, o Estado costeiro, tendo em conta os melhores dados científicos de que disponha, tem o dever de assegurar, por meio de medidas apropriadas de conservação e gestão, que a preservação dos recursos vivos da sua ZEE não seja ameaçada por um excesso de captura.

Após a identificação dos espaços marítimos, tor- na-se possível adentrar, de forma específica, na questão da definição da jurisdição penal em crimes cometidos a bordo de embarcações mercantes, em passagem inocente, no mar territorial brasileiro.

\section{A passagem inocente e a jurisdição penal brasileira}

\subsection{Conceito de Passagem Inocente}

Primeiramente, vale lembrar que, quanto à soberania no mar territorial, a jurisprudência brasileira é pacifica, entendendo, inclusive, que os navios estrangeiros estão sujeitos à jurisdição civil e penal do Estado em cujas águas se encontrem, exceto os navios militares e os de Estado, que gozam de imunidade de jurisdição e apenas podem receber ordem de retirada imediata.

Entretanto, a própria jurisprudência prevê que, mesmo os navios se submetendo às leis brasileiras, há o direito dos outros navios estrangeiros de percorrer esse espaço marítimo em face da passagem inocente ou por motivo de força maior e grave dificuldade, vide:

ADMINISTRATIVO. AUTO DE INFRAÇÃO. ESTADA IRREGULAR EM TERRITÓRIO NACIONAL. AUTUAÇÃO DA TRIPULAÇÃO MARÍTIMA E DO ARMADOR. LEGITIMIDADA ATIVA. ARTIGO $\underline{125}$, II E VII DA Lei $\mathrm{n}^{\circ}$ 6.815/80. ILEGITIMIDADE E ILEGALIDADE DOS ATOS ADMINISTRATIVOS NÃO DEMONSTRADAS.

1. Os tripulantes marítimos de embarcação estrangeira, autuados por violação ao artigo $\underline{125}$, $\underline{\text { II }}$, da Lei no ${ }^{\circ} \underline{6.815} / 80$, têm legitimidade ativa para ajuizar demanda objetivando a anulação do ato administrativo.

2. A Lei $n^{\circ}$ 8.617/93, que trata sobre o mar territorial, a zona contígua, a zona econômica exclusiva e a plataforma continental brasileiros dispõe, em seu $\operatorname{artigo} \underline{2}^{\circ}$, que a soberania do Brasil estende-se ao mar territorial, ao espaço aéreo sobrejacente, bem como ao seu leito e subsolo. Tal entendimento já havia previsão na Convenção das Nações Unidas sobre o Direito do Mar (Montego Bay, Jamaica), de 10 de dezembro de 1982, que define conceitos do direito internacional costumeiro e estabelece os princípios gerais da exploração dos recursos naturais do mar, o qual passou a viger no Brasil através do Decreto $\mathrm{n}^{\circ} \underline{1.530}$, de 22 de junho de 1995. 3. Os navios estrangeiros estão sujeitos à jurisdição civil e penal do Estado em cujas águas se encontrem, exceto os navios militares e os de Estado, que gozam de imunidade de jurisdição, e os navios estrangeiros em passagem inocente pelo no mar territorial, definida como passagem contínua, rápida e ordeira (art. 17 da Con- 
venção das Nações Unidas sobre o Direito do Mar). 4. A entrada de estrangeiro em território nacional se dará por locais onde houver fiscalização de órgãos competentes dos Ministérios da Saúde, Justiça e Fazenda. Por tal motivo, cabe ao estrangeiro regularizar sua permanência no território nacional. No entanto, estando ele empregado em empresa transportadora, passa a ser do transportador a responsabilidade pela entrada, permanência e retirada de estrangeiros marítimos do território nacional, como se observa no artigo $\underline{23}$ da Lei $n^{\circ} \underline{6.815} / 80$. 5. Esta Corte tem deliberado que apenas em casos de decisão teratológica, com abuso de poder ou em flagrante descompasso com a Constituição, a lei ou com a orientação consolidada de Tribunal Superior ou deste tribunal justificaria sua reforma pelo órgão ad quem, em agravo de instrumento, sendo certo que o pronunciamento judicial impugnado não se encontra inserido nessas exceções. 6. Agravo de instrumento conhecido e provido em parte. ${ }^{15}$

$\mathrm{O}$ direito de passagem inocente está previsto no art. $4^{\circ}$, inciso XXII e $5^{\circ}$, inciso XV da Constituição Federal de 1988, que prescrevem, respectivamente, que: "Pode se estender em tempo de guerra somente por expressa autoridade do Presidente" e "É livre a locomoção no território marítimo em tempo de paz".

O direito de passagem inocente é reconhecido aos navios de todas as nacionalidades e é considerado pela CNUDM, no seu artigo 17, como um direito dada aos navios de qualquer Estado, costeiro ou sem litoral, de atravessar o mar territorial de um Estado, tendo em vista o livre comércio.

De acordo com o previsto no artigo 18 da Convenção das Nações Unidas sobre o Direito do Mar, passagem significa a possibilidade de navegação pelo mar territorial de outros Estados soberanos, desde que tenha ou a finalidade de atravessar esse mar sem penetrar nas águas interiores e nem fazer escala num ancoradouro ou instalação portuária situada fora das águas interiores ou tenha a finalidade de se dirigir para as águas interiores ou delas sair ou fazer escala num desses ancoradouros ou instalações portuárias.

Ainda de acordo com o artigo 18 da CNUDM, a passagem deverá ser contínua e rápida. Entretanto, a passagem inocente poderá compreender o parar e o fundear, mas apenas na medida em que tais procedimentos constituam incidentes comuns de navegação ou que sejam impostos por motivos de força ou por dificuldade grave, ou tenham por fim prestar auxílio a pessoas a navios ou aeronaves em perigo ou em dificuldade grave.

A passagem será considerada inocente desde que não seja prejudicial à paz, à boa ordem ou à segurança do Brasil, devendo ser contínua e rápida, conforme o disposto no art. $3^{\circ}, \S 1^{\circ}$, da Lei no 8.617/93 e no artigo 19 da CNUDM.

\subsection{Os crimes cometidos dentro de embarcação es- trangeira em Passagem Inocente}

Pode-se asseverar que, no tocante à jurisdição no mar territorial, a regra geral é a sujeição dos navios estrangeiros à lei penal brasileira, inclusive a própria Convenção estabelece, no artigo 25, que o Estado Costeiro tem o direito de, no seu mar territorial, tomar todas as medidas necessárias para impedir as passagens não inocentes.

O Código de Direito Penal brasileiro estabelece no artigo $5^{\circ}, \S 2^{\circ}$ que: É também aplicável a lei brasileira aos crimes praticados a bordo de aeronaves ou embarcações estrangeiras de propriedade privada, achando-se aquelas em pouso no território nacional ou em voo no espaço aéreo correspondente, e estar em porto ou mar territorial do Brasil.

Contudo, a doutrina e a jurisprudência compreendem que a interpretação dos parágrafos de um determinado artigo fica submetido à "cabeça do artigo". Quando se examina o disposto no artigo $5^{\circ}$, caput e a forma como a Convenção de Montego Bay (CNUDM) normatizou a matéria, resta claro que a lei penal brasileira não é aplicável, salvo em algumas exceções, para os crimes cometidos em navios estrangeiros que, mesmo dentro do mar territorial, estejam em passagem inocente.

$\mathrm{O}$ artigo $5^{\circ}$, caput do nosso Código Penal, estabelece que aplica-se a lei brasileira ao crime cometido no território nacional, desde que não haja prejuízo as convenções, tratados e regras de direito internacional.

Acerca da jurisdição penal para os crimes cometidos em navio estrangeiro em passagem inocente, a Convenção das Nações Unidas sobre o Direito do Mar, no artigo 27, determina que "a jurisdição penal do Estado costeiro não será exercida a bordo de navio estrangeiro que passe pelo mar territorial com o fim de deter qualquer pessoa ou de realizar qualquer investigação, com relação à infração criminal cometida a bordo desse navio durante a sua passagem [...]". 
A Convenção ainda impõe mais uma limitação ao poder de punir do Estado costeiro, conforme se depreende do seu artigo 27, número 5. A referida disposição normativa estabelece que, salvo as exceções previstas na própria Convenção, o Estado costeiro não poderá, desde que a embarcação estrangeira, procedente de um porto estrangeiro, esteja em passagem inocente e sem adentrar em águas interiores, exercer qualquer medida de caráter penal a bordo de um navio estrangeiro que passe pelo mar territorial, para deter ou até mesmo investigar qualquer pessoa que se relacione com qualquer delito que tenha sido cometido antes do navio ter entrado no território do Estado costeiro.

Destaca-se que, atualmente, a importância da interação dinâmica entre direito internacional e o direito interno no âmbito de proteção de direitos, considerando que este fortalece o próprio Direito, e se justifica na medida em que cumpre a sua missão última de fazer justiça. No presente contexto, o direito internacional e o direito interno interagem e se auxiliam, apontando na mesma direção, coincidindo no propósito básico e último de ambos da proteção do ser humano ${ }^{16}$.

Entretanto, ainda na esteira do artigo 27, alínea "a", "b" e "c", só haverá jurisdição do Estado costeiro nos seguintes casos: se a infração criminal tiver consequências para o Estado costeiro; se a infração criminal for de tal natureza que possa perturbar a paz do país ou a ordem no mar territorial; se a assistência das autoridades locais tiver sido solicitada pelo capitão do navio ou pelo representante diplomático ou funcionário consular do Estado de bandeira; ou se essas medidas forem necessárias para a repressão do tráfico ilícito de estupefacientes ou de substâncias psicotrópicas.

A Convenção de Direito Internacional Privado (Código Bustamante, 1929), da qual o Brasil é signatário, estabelece no Livro Terceiro quem estaria isento das leis penais de cada Estado contratante. O art. 301, referindo-se também sobre as isenções, afirma que: "O mesmo sucede com os delitos cometidos em águas territoriais ou espaço aéreo nacional, em navios ou aeronaves mercantes estrangeiros, se não têm relação alguma com o país e seus habitantes, nem perturbam a sua tranquilidade".

16 TRINDADE, Antônio Augusto Cançado. Direito internacional e direito interno: sua interação na proteção dos direitos humanos. Disponível em: <http://www.pge.sp.gov. br/centrodeestudos/bibliotecavirtual/instrumentos/introd.htm>. Acesso em: 27 jul. 2016.
Há decisões nos tribunais pátrios que fazem expressa referência ao Código Bustamante e a sua aplicabilidade normativa, por exemplo:

PENAL. CRIME COMETIDO A BORDO DE NAVIO MERCANTE. APLICAÇÃO DA LEI PENAL BRASILEIRA. CÓDIGO DE BUSTAMANTE.

- AO CRIME COMETIDO EM ÁGUAS TERRITORIAIS DO BRASIL A BORDO DE NAVIO MERCANTE, DE OUTRA NACIONALIDADE, SE APLICA A LEI PENAL BRASILEIRA, AFASTADA A INCIDÊNCIA DO ART. 301 DO CÓDIGO DE BUSTAMANTE, POR IMPORTAR A SUA PRATICA EM PERTURBAÇÃO DA TRANQUILIDADE DO NOSSO PAÍS, TANTO MAIS QUANDO OS PAIISES DE NACIONALIDADE DE AUTOR E VITIMA E DA BANDEIRA DO NAVIO NÃO SÃO SIGNATÁRIOS DA CONVENÇÃO DE HAVANA DE $1928^{17}$.

Sem dúvida alguma, a afirmação que o Estado costeiro perde, salvo algumas exceções, o poder de punir os delitos cometidos nos navios estrangeiros que estejam em passagem inocente no seu mar territorial, confirma-se integralmente.

Porém, nenhuma das convenções examinadas estabelece a competência para investigar e processar os delitos cometidos na situação já referida, o que acaba tornando a questão problemática, pois, em tese, há dois princípios que poderiam dar uma solução prática a questão e, como fica claro na decisão abaixo colacionada, esses princípios são o da nacionalidade e o da bandeira.

PROCESSUAL PENAL - CRIME PRATICADO POR ESTRANGEIRO CONTRA ESTRANGEIRO, EM NAVIO MERCANTE TAMBÉM ESTRANGEIRO, EM ÁGUAS TERRITORIAIS BRASILEIRAS - COMPETÊNCIA DA JUSTIÇA BRASILEIRA [...]. 1. NÃO SENDO O PAIS DA NACIONALIDADE DO PACIENTE, NEM O DA BANDEIRA DO NAVIO ONDE FOI COMETIDO O CRIME, SIGNATÁRIOS DO CÓDIGO INTERNACIONAL PRIVADO (CÓDIGO DE BUSTAMANTE), E INEXISTINDO QUALQUER OUTRA EXCEÇÃO PREVISTA EM TRATADOS, CONVENÇÕES OU NORMAS DE DIREITO INTERNACIONAL, FIRMA-SE A COMPETÊNCIA DA JUSTIÇA BRASILEIRA PARA O PROCESSO E O JULGAMENTO DA AÇÃO PENAL. (CÓDIGO DE BUSTAMANTE, ART. 2; CÓDIGO PENAL BRASILEIRO, ART. 5, PARAG. 2) ${ }^{18}$.

17 Superior Tribunal de Justiça - STJ. RHC 853/BA. Relator: Min. Dias Trindade. Fonte: RT.v.00665. p. 00353. Publicado no DJ de 03.12.1990.

18 TRF $1^{\circ}$ Região. HC 90.01.06573-2. Relator: Juiz Murat Valadares. Órgão Julgador: Quarta Turma. Fonte: DJ 17 /09/1990. p. 21208. 
Percebe-se que o Julgador brasileiro se valeu dos dois princípios para fixar a competência brasileira, mas a problemática permanece na medida que, hipoteticamente falando, essa mesma situação ocorresse com signatários do Código Bustamante, por exemplo. Ainda no exercício das conjecturas, o Brasil, na situação hipotética em glosa, perderia a competência penal, pois é assim que determina o Código Bustamante e, da mesma maneira, a Convenção de Montego Bay.

Mas, com o Brasil impossibilitado de exercer o poder de punir os crimes cometidos em embarcações estrangeiras em passagem inocente - lembrando que tanto o País da bandeira da embarcação quanto o País da nacionalidade dos agentes são signatários do Código Bustamante ou da Convenção de Montego Bay -, surge a necessidade de se estabelecer qual o Estado tem a jurisdição penal para punir os indivíduos que, porventura, cometam infrações penais.

O primeiro passo na discussão da questão é examinar os dois princípios da extraterritorialidade já citados. O princípio da nacionalidade afirma que a lei penal do Estado se aplica a todos os seus cidadãos, independentemente do lugar onde tenha ocorrido o delito ${ }^{19}$. Como assevera Asúa ${ }^{20}$, esse princípio surge como uma exacerbação de doutrinas nacionalistas, o que justifica a importância e a relevância desse sistema de aplicação da lei penal no espaço nos Estados totalitários. Não é sem motivo que os ordenamentos jurídicos democráticos o adotam com reserva, impondo uma série de restrições a sua aplicação, como, por exemplo, no sistema jurídico-penal brasileiro.

O princípio da bandeira ou pavilhão estabelece como competente o Estado que registrou a embarcação para aplicar a sua lei penal. Pode-se afirmar que o Brasil adotou tal sistema para aplicar a lei interna quando ocorrer um delito dentro de um navio privado de bandeira brasileira que está em território estrangeiro, mas ali não tiver sido julgado ${ }^{21}$.

Já em relação às embarcações públicas ou mesmo as privadas que se encontrem em alto-mar, o Código Penal brasileiro, no seu artigo $5^{\circ}, \S 1^{\circ}$, considera que ambas

19 RAMÍREZ, Juan J. Bustos; MALARÉE, Hernán Hormazábal. Lecciones de derecho penal. Madrid: Trotta, 1997. v. 1. p. 112.

20 ASÚA, Luis Jiménez. La ley y el delito: princípios de derecho penal. Buenos Aires: Sudamericana, 1958. p. 162. são consideradas como extensão do território nacional, assim disposto:

Artigo $5^{\circ}, \S 1^{\circ}$. Para os efeitos penais, consideram-se como extensão do território nacional as embarcações e aeronaves brasileiras, de natureza pública ou a serviço do governo brasileiro onde quer que se encontrem, bem como as aeronaves e as embarcações brasileiras, mercantes ou de propriedade privada, que se achem, respectivamente, no espaço aéreo correspondente ou em alto-mar' ${ }^{22}$.

\section{Conclusão: o princípio da bandeira e a jurisdi- ção penal nos delitos cometidos a bordo de navios estrangeiros em passagem inocente}

Como é possível observar ao longo do presente artigo, a grande maioria dos ordenamentos jurídicos adota o critério da territorialidade como regra geral para aplicar a sua lei penal. Esse sistema consegue acomodar bem o exercício do poder punitivo de cada Estado soberano. Todavia, essa regra geral precisa ser complementada com princípios acessórios, que possibilitam a aplicação extraterritorial de uma lei penal.

O mar territorial, que já fora objeto de muitas discussões quanto a sua extensão, mas todas elas resolvidas pela Convenção das Nações Unidas sobre o Direito do Mar, tem o limite de 12 milhas náuticas e faz parte do território do Estado costeiro, e, por conseguinte, está sujeito a soberania do respectivo Estado.

A regra geral impõe que a lei penal brasileira, por exemplo, aplicar-se-á a todos os crimes cometidos em navios estrangeiros, desde que já tenham adentrado em mar territorial, consoante disposição legal.

Restou exposto que o Código Bustamante e, precipuamente, a Convenção de Montego Bay, normatizaram um impedimento para o pleno exercício do poder de punir dos Estados signatários, uma vez que não cabe mais ao Estado Costeiro investigar e punir os crimes ocorridos dentro do seu mar territorial em navio estrangeiro que esteja em passagem inocente, salvo poucas exceções também previstas nas Convenções.

Firmou-se, consequentemente, a exclusão da competência do Estado costeiro para punir os delitos nas condições narradas, todavia também é importante definir o Estado que poderá exercer o seu poder de punir, e, nesse caso, não é possível se socorrer das Convenções

22 Código Penal Brasileiro, artigo $5^{\circ}, \S 1^{\circ}$ 
supracitadas. É preciso buscar nos princípios da extraterritorialidade a solução.

O princípio da nacionalidade, baseado nas doutrinas nacionalistas, é mais adequado aos regimes totalitários e passa por um irrefreável processo de desuso pelos Estados Nacionais.

Sob outra perspectiva, acredita-se que o princípio do pavilhão (bandeira), principalmente quando este é examinado de forma mais detida. No fim das contas, o princípio da territorialidade sofre uma expansão no ordenamento jurídico brasileiro em face do princípio da bandeira, conforme visto e previsto no artigo $5^{\circ}, \$ 1^{\circ}$, passando a considerar que os fatos cometidos a bordo de navios com a bandeira brasileira em alto-mar, equivale funcionalmente aos fatos cometidos em território nacional.

É perceptível que o princípio da bandeira é próximo ao da territorialidade, pois estende a soberania do País da bandeira da embarcação privada para além dos contornos estabelecidos pela territorialidade, tornando-o competente para aplicar o seu Jus Puniendi e, desse modo, processar e julgar os delitos cometidos a bordo do navio privado.

Não se pode deixar de reconhecer que os delitos cometidos nos navios privados em alto-mar são análogos aos cometidos a bordo de embarcações privadas em passagem inocente pelo mar territorial de outro Estado soberano, por força de disposições normativas previstas tanto no Código Bustamante quanto na Convenção de Montego Bay.

Defende-se, à guisa de conclusão, que o País da bandeira da embarcação estrangeira em passagem inocente é o detentor da jurisdição penal para processar os crimes ocorridos dentro do navio.

\section{Referências}

ASÚA, Luis Jiménez. La ley y el delito: princípios de derecho penal. Buenos Aires: Sudamericana, 1958.

ASÚA, Luis Jiménez. Tratado de derecho penal. Buenos Aires: Losada, 1950. t. 2.

BONAVIDES, Paulo. Ciência política. 10. ed. São Paulo: Malheiros, 2000.

BRANDÃO, Cláudio. Curso de direito penal: parte geral. Rio de Janeiro: Forense, 2010.

CONDE, Francisco Muñoz; ARÁN, Mercedes García. Derecho penal: parte general. Valência: Tirant Lo Blanch, 2004.
DIAS, Jorge de Figueiredo. Direito penal: parte geral. Coimbra: Coimbra, 2007. t. 1.

FERRI, Enrico. Princípios de direito criminal: o criminoso e o crime. Campinas: Bookseller, 2003.

GRISPIGNI, Filippo. Derecho penal italiano: las normas penales sintéticamente consideradas. Buenos Aires: Depalma, 1949. v. 1.

JESCHECK, Hans-Heinrich. Tratado de derecho penal: parte general. Granada: Comares, 2002.

MAZZUOLI, Valério de Oliveira. Tribunal penal internacional e o direito brasileiro. São Paulo: Premier Máxima, 2005.

RAMÍREZ, Juan J. Bustos; MALARÉE, Hernán Hormazábal. Lecciones de derecho penal. Madrid: Trotta, 1997. v. 1 .

REZEK, Francisco. Direito internacional público. 10. ed. São Paulo: Saraiva, 2005.

RIPOLLÉS, Antonio Quintano. Tratado de derecho penal internacional e internacional penal. Madrid: Instituto Francisco de Vitória, 1955. v. 1.

TRINDADE, Antônio Augusto Cançado. Direito internacional e direito interno: sua interação na proteção dos direitos humanos. Disponível em: <http://www.pge.sp. gov.br/centrodeestudos/bibliotecavirtual/instrumentos/ introd.htm>. Acesso em: 27 jul. 2016. 